\title{
The Relationship of LDH and Hematological Parameters with Ischemic Volume and Prognosis in Cerebrovascular Disease
}

\author{
Tufan Alatlı, Salih Kocaoglu ${ }^{1}$ and Emrah Akay ${ }^{2}$ \\ ${ }^{1}$ Department of Emergency, Faculty of Medicine, Balikesir University, Balikesir, Turkey \\ ${ }^{2}$ Department of Radiology, Faculty of Medicine, Balikesir University, Balikesir, Turkey
}

\begin{abstract}
Objective: To determine whether lactate dehydrogenase (LDH), platelet-lymphocyte ratio (PLR), neutrophil-lymphocyte ratio (NLR), and lymphocyte-monocyte ratio (LMR) values can be used as a prediction for their relationship with stroke volume (SV) and for in-hospital mortality in stroke patients in Emergency Department (ED).

Study Design: Analytical study.

Place and Duration of Study: Balikesir University, Turkey from 24/03/2021 to 30/06/2021.

Methodology: Patients aged 18 years or older, diagnosed with stroke in ED, were included in the study. Stroke volumes were calculated from diffusion-weighted images (DWi) with 3D slicer software using image-based semi-automatic and manual segmentation methods.

Results: Of the 265 patients, 128 (48.3\%) were males. SV was significantly higher in the non-survivor group than in the survivor group ( $p=0.007)$. NLR was significantly higher in the non-survivor group than in the survivor group $(p=0.018)$.

Conclusion: The ratios of NLR and SV stand out as practical parameters for the estimation of mortality, prognosis, and management of patients diagnosed with acute stroke. Taking into account, these parameters in the diagnosis process and prognosis management in EDs will provide convenience.
\end{abstract}

Key Words: Ischemia, NLR, Stroke volume, Cerebrovasular accident, Prognosis.

How to cite this article: Alatlı T, Kocaoglu S, Akay E. The Relationship of LDH and Hematological Parameters with Ischemic Volume and Prognosis in Cerebrovascular Disease. J Coll Physicians Surg Pak 2022; 32(01):42-45.

\section{INTRODUCTION}

Cerebrovascular diseases (CVD) are among the most common causes of death in our country as well as in the world. ${ }^{1}$ It is also a serious cause of morbidity and mortality. Approximately $15 \%$ of stroke cases are classified as hemorrhagic, and $85 \%$ are ischemic CVD. ${ }^{2}$ Ischemic CVD usually develops due to embolism-induced arterial occlusion or, more rarely, vascular thrombosis. ${ }^{3}$ There is also increased evidence that inflammation plays an important role in the pathophysiology of ischemic stroke. ${ }^{4}$ The duration of symptoms is very important in the diagnosis of CVD. Cranial imaging time can sometimes lead to serious time losses that may stem from hospital or the patient. These delays are directly related to mortality and morbidity in patients with CVD. All these make stroke management important for Emergency Department (ED) physicians.

Correspondence to: Dr. Tufan Alatl, Department of Emergency, Faculty of Medicine, Balikesir University, Balikesir, Turkey

E-mail:drtufanalatli@gmail.com

Received: June 21, 2021; Revised: November 02, 2021;

Accepted: November 29, 2021

DOI: https://doi.org/10.29271/jcpsp.2022.01.42
For this reason, it is obvious that revealing prognostic parameters will help ED physicians in terms of quick and accurate decision-making in stroke management. Thus, it is required to find helpful parameters in preventing possible time losses and reducing morbidity and mortality rates in the future.

The aim of this study was to find out whether lactate dehydrogenase(LDH), platelet-lymphocyteratio(PLR), neutrophil-lymphocyte ratio (NLR), and lymphocyte-monocyte ratio (LMR) values can be used as a prediction for their relationship with ischemic tissue volume and for diagnosis, and in-hospital mortality in patients diagnosed with ischemic stroke in ED.

\section{METHODOLOGY}

Ethics Committee approval was obtained from the Ethics Committee of Faculty of Medicine, Balikesir University (E.23964; dated: March 31, 2021). The data was collected retrospectively, and the patients, who were aged 18 orolderand diagnosed with ischemic stroke in ED, were included in the study. Patients with hemorrhagic CVD, pregnancy, comorbidities, and referred to another institution were excluded from the study. Laboratory results and diffusion MRIs were obtained from the hospital information system and patient files. Brain MRI examination was performed with a $1.5 \mathrm{~T}$ scanner (Ingenia, Philips 
Healthcare, Netherlands). The routine MRI protocol included diffusion-weighted imaging (DWI), using single-shot spin-echo echo-planar imaging with 500 and $1000 \mathrm{~mm} / \mathrm{s}$ B values, and axial T2-weighted imaging (Turbo Spin Echo (TSE)) with TSE factor 15 in all patients. Stroke volumes were calculated from DWIs with 3D slicer software using image-based semi-automatic and manual segmentation methods. ${ }^{5}$

Shapiro-Wilk test was used to test the normality of variables. Continuous variables were presented as mean and median values (minimum-maximum), since they did not fit a normal distribution. Mann-Whitney U-test was conducted to compare two independent groups. Categorical variables were expressed by counts and percentages. Comparisons between the groups were made with the Pearson Chi-square test for categorical variables. The relationship between stroke volume and laboratory variables (LDH, PLR, and LMR) were evaluated with Spearman's correlation coefficient. The significance level was taken as $\alpha=$ 0.05. Statistical analyseswere performed on the IBMSPSS statistics version 23.0 (IBM Corp., USA).

\section{RESULTS}

Of the 265 patients included in this study, 128 (48.3\%) were males, and 137 (51.7\%) were females. The median age of the patients was 72.0 (min-max: 18.0-93.0) years. There were 21 $(7.9 \%)$ patients in the non-survivor group and $244(92.1 \%)$ patients in the survivor group. The age of the patients, who died, were significantly higher than those who survived $(p=0.041)$. There was no significant difference between the two groups in terms of gender $(p=0.329$, Tablel).

Table I: Comparison between the survivor and non-survivor groups regarding demographic characteristics.

\begin{tabular}{|l|c|c|c|c|}
\hline & $\begin{array}{c}\text { Total } \\
(\mathbf{n = 2 6 5 )}\end{array}$ & $\begin{array}{c}\text { Non-survivor } \\
(\mathbf{n = 2 1 )}\end{array}$ & $\begin{array}{c}\text { Survivor } \\
(\mathbf{n = 2 4 4 )}\end{array}$ & p-value* \\
\hline $\begin{array}{l}\text { Age (years), } \\
\text { median (min-max) }\end{array}$ & $\begin{array}{c}72.0 \\
(18.0-93.0)\end{array}$ & $\begin{array}{c}77.0 \\
(54.0-93.0)\end{array}$ & $\begin{array}{c}71.0 \\
(18.0-92.0)\end{array}$ & 0.041 \\
\hline Gender, n (\%) & $128(48.3)$ & $8(38.1)$ & $120(49.2)$ & \multirow{2}{*}{0.329} \\
\hline Male & $137(51.7)$ & $13(61.9)$ & $124(50.8)$ & \\
\hline Female &
\end{tabular}
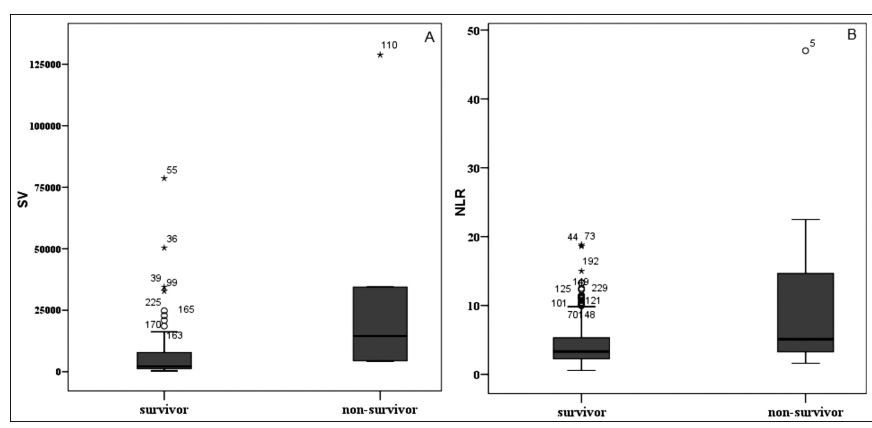

Figure 1: Box-plots for the (A) SV and (B) NLR in the survivor and non-survivorgroups.

Outliers are values (marked with a small circle) between 1.5 IQRs and 3 IQRs from the end of the box. Extreme values (marked with a star) are values more than 3 IQRs from the end of the box. SV: Stroke volume (mm3), NLR: Neutrophil-to-lymphocyte ratio.
Stroke volume (SV) was significantly higher in the non-survivor group than in the survivor group ( $p=0.007$ ). We also found that NLR was significantly higher in the non-survivor group than in the survivor group $(p=0.018$ ) (Figure 1 ). There was no significant difference between the two groups in terms of LDH, PLR, and LMR. The clinical characteristics of the patients are presented in Table II.

There was no significant correlation between the stroke volume and LDH $(r=0.210, p=0.120), \operatorname{NLR}(r=0.028, p=0.840), \operatorname{PLR}(r$ $=-0.057, p=0.674)$, and LMR $(r=0.170 p=0.211)$ in all patients. When the authors evaluated correlations separately in terms of gender, no significant relationship was found among stroke volume and LDH, NLR, PLR, and LMR for both female and male patients (Table III).

\section{DISCUSSION}

A small proportion of CVDs (3.7\%) develop under the age of 45 , and according to the study of Coşkun et al., the average age of occurrence of CVD, especially in western societies, is 75 years. ${ }^{6,7}$ Mortality has been reported as $5.5-8 \%$ in ischemic CVDs. ${ }^{8,9}$ The results of this study are similar to those in the literature. On the other hand, the study revealed results different from those of the literature, showing that the mean age of patients who developed mortality in the 3-month period after CVD was lower than those who did not. While no relationship was found between mortality and age, there were studies reporting that mortality was higher in the group with patients aged over 65 years old. ${ }^{10,11}$

Detection of cerebral infarct area is very important in terms of treatment method and success in EDs; and is recommended in patient management. ${ }^{3}$ Although computerised brain tomography (CT) is the first choice in many centres for imaging, tissue changes within minutes and days are best detected with diffusion-weighted MRI imaging. ${ }^{2-12}$

The ischemic volume rate is a clear indicator of the ischemic area. Mortality in patients with CVD can reach up to $8 \%{ }^{9}$ Although no correlation was found between SV and mortality in the results of the study conducted by Kasike et al., a positive correlation was found between SV and mortality in this study. ${ }^{10}$

Slowing blood flow-bound neutrophils are one of the first parameters to increase. ${ }^{13}$ Kasikci et al. determined that high PLR was associated with poor prognosis and low LMR with mortality. Low LMR is a risk factor for atherosclerosis. Low LMR value in the early period was found to be more significant, especially in terms of poor prognosis, and the cutoff point was stated as $2.99 .{ }^{10,13,14} \mathrm{High}$ neutrophil count, that is seen in the early period, increases ischemic brain damage. ${ }^{10-15}$ Low lymphocyte count is associated with poor functional recovery. ${ }^{10}$ Total leukocyte count shows a strong positive correlation with SV, but it is not correlated with lymphocytes. ${ }^{16}$ Neutrophils, lymphocytes, monocytes, and NLR are associated with neuronal damage and the course of stroke as a result of immune response activation in CVD. ${ }^{13}$ 
Table II: Comparison between the survivor and non-survivor groups regarding laboratory characteristics.

\begin{tabular}{|c|c|c|c|c|c|c|c|}
\hline \multirow[b]{2}{*}{ Variables } & \multicolumn{2}{|r|}{ Total } & \multicolumn{2}{|r|}{ Non-survivor } & \multicolumn{2}{|r|}{ Survivor } & \multirow[b]{2}{*}{ p-value ${ }^{*}$} \\
\hline & $\mathbf{n}$ & $\begin{array}{c}\text { median } \\
(\min -\max )\end{array}$ & $n$ & $\begin{array}{c}\text { median } \\
(\min -\max )\end{array}$ & $\mathbf{n}$ & $\begin{array}{c}\text { median } \\
(\min -\max )\end{array}$ & \\
\hline $\mathrm{SV}\left(\mathrm{mm}^{3}\right)$ & 58 & $\begin{array}{c}2625.2 \\
(354.2-128843.0)\end{array}$ & 6 & $\begin{array}{c}14508.1 \\
(4238.2-128843.0)\end{array}$ & 52 & $\begin{array}{c}2134.9 \\
(354.2-78628.9)\end{array}$ & 0.007 \\
\hline $\mathrm{LDH}$ & 252 & $\begin{array}{c}218.0 \\
(17.0-2312.0)\end{array}$ & 21 & $\begin{array}{c}229.0 \\
(141.0-399.0)\end{array}$ & 231 & $\begin{array}{c}215.0 \\
(17.0-2312.0)\end{array}$ & 0.130 \\
\hline NLR & 263 & $\begin{array}{c}3.5 \\
(0.6-47.0) \\
\end{array}$ & 21 & $\begin{array}{c}5.1 \\
(1.6-47.0) \\
\end{array}$ & 242 & $\begin{array}{c}3.3 \\
(0.6-18.8) \\
\end{array}$ & 0.018 \\
\hline PLR & 263 & $\begin{array}{c}158.7 \\
(2.3-1215.0)\end{array}$ & 21 & $\begin{array}{c}190.0 \\
(57.2-1215.0)\end{array}$ & 242 & $\begin{array}{c}154.8 \\
(2.3-615.0)\end{array}$ & 0.057 \\
\hline LMR & 263 & $\begin{array}{c}3.0 \\
(0.2-26.0)\end{array}$ & 21 & $\begin{array}{c}2.8 \\
(0.5-9.0)\end{array}$ & 242 & $\begin{array}{c}3.0 \\
(0.2-26.0)\end{array}$ & 0.627 \\
\hline
\end{tabular}

Table III: Correlations between stroke volume and other laboratory variables.

\begin{tabular}{|l|l|l|l|l|}
\hline & & All patients & Males & Females \\
\hline \multirow{2}{*}{ LDH } & $r$ & 0.210 & 0.100 & 0.311 \\
\cline { 2 - 5 } & $p$-value & 0.120 & 0.608 & 0.115 \\
\hline \multirow{2}{*}{ NLR } & $r$ & 0.028 & 0.006 & 0.069 \\
\cline { 2 - 5 } & $p$-value & 0.840 & 0.974 & 0.731 \\
\hline \multirow{2}{*}{ PLR } & $r$ & -0.057 & -0.098 & 0.012 \\
\cline { 2 - 5 } & $p$-value & 0.674 & 0.613 & 0.951 \\
\hline \multirow{2}{*}{ LMR } & r & 0.170 & -0.160 & 0.178 \\
\cline { 2 - 5 } & $p$-value & 0.211 & 0.406 & 0.375 \\
\hline
\end{tabular}

NLR was found to be significantly higher in early mortality, and the cutoff value was calculated as 4,12. Moreover, WBC was found as insignificant. ${ }^{11}$ In this study, a positive correlation was found only between high NLR and mortality. PLR and LMR values did not have a relationship with mortality.

LDH is an enzyme used to obtain energy in all cells in the body and has a role in the energy mechanism. It also has a very important function in neuron cells. It is a byproduct of anaerobic metabolism. It is released into the bloodstream by injured neurons and glial cells. ${ }^{17,18}$ Its volume in the blood increases in cell necrosis or damage. The increased volume of $\mathrm{LDH}$ in the brain tissue increases the lactate level and exerts a neuroprotective effect. ${ }^{18}$ Lactate has been shown to be neuroprotective in animal experiments and is used as an energy source in brain tissue. ${ }^{19,20}$ The creased LDH levels in blood serum may reflect damage to neurons. ${ }^{17}$ However, no study was found showing the relationship between LDH and acute CVD prognosis and mortality. Elevated lactate was found to be associated with 3-month mortality. ${ }^{9}$ However, there are also studies showing that lactate is not associated with prognosis. ${ }^{21}$ While a relationship was reported between high lactate and SV, no relationship was found with 3-month mortality. ${ }^{22}$ According to the results of this study, no relationship was found between LDH and mortality; and its relationship with SV could not be demonstrated.

The study had some limitations. Limited number of patients undergo DW-MRI in ED, because of instablity, technical draw- backs at machine in some days and referral other hospital for hospital hospital occupancy. Patients brains were scanned by computerised tomography and referred to other hospital with clinic outcomes. Patients with multiple millimetric infarcts were excluded due to computational difficulties. This situation limited the number of patients, who were analysed for SV. This study was single-centre and retrospective. It needs to be supported by larger, prospective, and multi-centre studies.

\section{CONCLUSION}

In the whole patient group, NLR value and SV were found to be correlated with 3-month patient mortality. These values can be used as important parameters in the management of patients with ischemic stroke, and estimation of prognosis in emergency departments.

\section{ETHICAL APPROVAL:}

Ethics Committee approval was obtained from the Ethics Committee of Faculty of Medicine, Balikesir University (E.23964; dated: March 31, 2021).

\section{PATIENTS' CONSENT:}

Since the study was a retrospective archive search, informed consents were not obtained from the patients.

\section{CONFLICT OF INTEREST:}

The authors declared no conflict of interest.

\section{AUTHORS' CONTRIBUTION:}

TA: Conceived and designed the study, data collection, statistic analyses, paper write-up, and result compilation.

SK: Data collection, discussion, result compilation, and proofreading.

EA: Data collection, ischemic area measurement, and result complitation.

\section{REFERENCES}

1. Olum Nedeni istatistikleri 2018,vTUIK. data.tuik.gov.tr/ Bulten/Index?p=Causes-of-Death-Statistics-2018-30626.

2. Sacco RL, Kasner SE, Broderick JP, Caplan LR, Connors JJ, Culebras A, et al. An updated definition of stroke forthe 21st 
Century a statement for healthcare professionals from the american heart association/american stroke association. Stroke 2013; 44(7):p.2064-89. doi: 10.1161/ STR.0b01 3e318296aeca.

3. Arslan S, Kızılkılıç O. Nöroradyolojide İleri BT Teknikleri ve Protokolleri. Trd Sem 2020; 8:66-79. doi: 10.5152/trs. 2020.835.

4. Waje-Andreassen U, Krakenes J, Ulvestad E, Thomassen L, Myhr KM, Aarseth J et al. IL-6: An early marker for outcome in acute Ischemic stroke. Acta Neurol Scand 2005; 111(6):360-5. doi: 10.1111/j.1600-0404.2005.00416.x.

5. Fedorov A, Beichel R, Kalpathy-Cramer J, Finet J, FillionRobin JC, Pujol S, et al. 3D Slicer as an Image computing platform for the quantitative ımaging network. Magn Reson Imaging 2012; 30(9):1323-41. doi: 10.1016/j.mri. 2012.05.001.

6. Walker AE, Robins M, Weinfeld FD. The national survey of stroke: Clinical findings. Stroke 1981; 12(2 Pt 2 Suppl 2): 113-44.

7. Coşkun O, İnan LE. Genc Hastalardaki iskemik inmede hematolojik risk faktörleri. Uluslararası Hematoloji-Onkoloji Dergisi 2006; 16(1):54-62.

8. El-Saed A, Kuller LH, Newman AB, Lopez O, Costantino J, McTigue K, et al. Geographic variations in stroke Incidence and mortality among older populations in four US communities. Stroke 2006; 37(8):1975-9. doi: 10.1161/ 01.STR. 0000231453.98473 .67$.

9. Jo S, Jeong T, Lee JB, Jin YH, Yoon J, Jun YK, et al. Initial hyperlactatemia in the ED is associated with poor outcome in patients with Ischemic stroke. Am J Emerg Med 2012; 30(3):449-55. doi: 10.1016/j.ajem.2011.12.019.

10. Kasikci MT, Yıldırım S. The relationship between hospital mortality and hematological parameters in acute Ischemic stroke patients. Med J Mugla Sitki Kocman Uni 2020; 7(1): 45-9.

11. Demir HA, Bildik F, Demir TG, Caliskan D, Sahnaoglu R, Gökçe EÖ. Complete blood count parameters and mortality in stroke patients. MKÜ Tıp Dergisi 2020; 11(41):95-102.

12. Jauch EC, Saver JL, Adams HP, Bruno A, Connors JJB, Demaerschalk BM, et al. Guidelines for the early management of patients with acute Ischemic stroke a guideline for healthcare professionals from the American heart association/american stroke association. Stroke 2013; 44(3):870-947. doi: 10.1161/STR.0b013e318284056a.
13. Anrather J, Iadecola C. Inflammation and stroke: An overview. Neurotherapeutics 2016; 13(4):661-70. doi: 10.1007/s13311-016-0483-X.

14. Ren H, Liu X, Wang L, Gao Y. Lymphocyte-to-monocyte ratio: A novel predictor of the prognosis of acute Ischemic stroke. J Stroke Cerebrovascular Dise 2017; 26(11): 2595-2602. doi: 10.1016/j.jstrokecerebrovasdis.2017.06. 019.

15. Herz J, Sabellek P, Lane TE, Gunzer M, Hermann DM, Doeppner TR. Role of neutrophils in exacerbation of brain Injury after focal cerebral Ischemia in hyperlipidemic mice. Stroke 2015; 46(10):2916-25. doi: 10.1161/STROKEAHA. 115.010620 .

16. Buck BH, Liebeskind DS, Saver JL, Bang OY, Yun SW, Starkman S, et al. Early neutrophilia is associated with volume of Ischemic tissue in acute stroke. Stroke 2008; 39(2):355-360. doi: 10.1161/STROKEAHA.107.490128.

17. Wen JY, Chen ZW. Protective effect of pharmacological preconditioning of total flavones of abelmoschl manihot on cerebral Ischemic reperfusion injury in rats. Am J Chinese Med 2007; 35(4):653-661. doi: 10.1142/S0192415 X07005144.

18. Chen ZX, Xu QQ, Shan CS, Shi YH, Wang Y, Chang RCC, et al. Borneol for regulating the permeability of the blood-brain barrier in experimental Ischemic stroke: preclinical evidence and possible mechanism. Hindawi Oxidative Med Cellular Longevity 2019:1-16. doi: 10.1155/2019/2936737.

19. Berthet C, Lei $H$, Thevenet J, Gruetter R, Magistretti PJ, Hirt L. Neuroprotective role of lactate after cerebral Ischemia. J Cerebral Blood Flow Metabolism 2009; 29(11):1780-9. doi: 10.1038/jcbfm.2009.97.

20. Castillo X, Rosafio K, Wyss MT, Drandarov K, Buck A, Pellerin $\mathrm{L}$, et al. A probable dual mode of action for both $\mathrm{L}$ - and $\mathrm{D}$-lactate neuroprotection in cerebral Ischemia. J Cerebral Blood Flow Metabolism 2015; 35(10):1561-9. doi: 10.1038/ jcbfm.2015.115.

21. Brouns R, Sheorajpanday R, Wauters A, De Surgeloose D, Marien P, De Deyn PP. Evaluation of lactate as a marker of metabolic stress and cause of secondary damage in acute Ischemic stroke or TIA. Clinica Chimica Acta 2008; 397(1-2):27-31. doi: 10.1016/j.cca.2008.07.016.

22. Caglayan T, Ozakin E, Ozdemir AO, Acar N, Canakci ME, Arslan $\mathrm{E}$, et al. The effect of blood lactate level on prognosis in patients with hemorrhagic and Ischemic cerebrovascular disease. Osmangazi J Med 2021; 115-121. 